\title{
Photoionization of 2,3-Dimethyl-2-Butanol (Thexyl Alcohol): Interaction Between the Charged and Expelled Fragments
}

\author{
John C. Traeger \\ Department of Chemistry, La Trobe University, Bundoora, Victoria, Australia \\ Thomas Hellman Morton \\ Department of Chemistry, University of California, Riverside, California, USA
}

\begin{abstract}
Photoionization studies of $\left(\mathrm{CH}_{3}\right)_{2} \mathrm{CHC}\left(\mathrm{CH}_{3}\right)_{2} \mathrm{OH}$ (tert-hexyl alcohol, also called thexyl alcohol) exhibit four fragmentations below $10 \mathrm{eV}$. As with other tertiary alcohols, no molecular ion is detected. The only ion observed at threshold corresponds to propane loss. Examination of a deuterated analogue, $\left(\mathrm{CH}_{3}\right)_{2} \mathrm{CHC}\left(\mathrm{CD}_{3}\right)_{2} \mathrm{OH}$, shows only loss of $\mathrm{C}_{3} \mathrm{H}_{7} \mathrm{D}$, implying that the fragment ion has the structure of ionized acetone enol. There is no evidence for reversible deuterium transposition, as has been reported for isotopomers of the homologous secondary alcohol $\left(\mathrm{CH}_{3}\right)_{2} \mathrm{CHCH}\left(\mathrm{CH}_{3}\right) \mathrm{OH}$. Propane loss from thexyl alcohol is attributed to intermediacy of ion-neutral complexes containing isopropyl radical and $O$-protonated acetone. Simple cleavage to give $O$-protonated acetone has an appearance energy $18 \mathrm{~kJ} \mathrm{~mol}^{-1}$ higher than that of propane loss. Thermochemical estimates and ab initio calculations both predict that methyl loss should have a lower threshold than the fragmentation leading to isopropyl loss, but experiments show the appearance energy to be $6 \mathrm{~kJ} \mathrm{~mol}^{-1}$ higher. This is consistent with previous reports of reverse activation barriers for methyl cleavages. Finally, formation of tert-hexyl cation, $\left(\mathrm{CH}_{3}\right)_{2} \mathrm{CHC}\left(\mathrm{CH}_{3}\right)_{2}^{+}$, is observed with an appearance energy comparable to that of methyl loss, substantially below that predicted for $\mathrm{OH}$ radical expulsion from the molecular ion. The comparatively low threshold of this fragmentation is ascribed to ion-pair formation (concomitant with hydroxide ion) directly from an electronically excited neutral. Interactions between charged and neutral fragments (including energetics, bond orders $<1$, and electrical charges on molecular fragments) are explored using a combination of DFT and $\mathrm{ab}$ initio methods, along with topological analysis using the Atoms in Molecules approach. (J Am Soc Mass Spectrom 2004, 15, 989-997) (c) 2004 American Society for Mass Spectrometry
\end{abstract}

$\mathrm{U}$ nimolecular ion decompositions in the mass spectrometer typically take place via the following sequence of events: a molecular ion is first produced, which subsequently fragments, either by simple bond fission or by rearrangement and then cleavage [1]. Over the past two decades, experiment and theory have provided new variations on this theme. In some instances, simple bond fissions do not lead directly to expulsion, but instead create ion-neutral complexes [2]. These transient intermediates consist of charged and neutral partners in orbit around their center of mass. The fragments are slow to recombine because of the rotational degrees of freedom liberated by loss of directed valence, as illustrated schematically by the species in brackets in eq 1 . Ion-neutral complexes

Published online June 9, 2004

Address reprint requests to Dr. J. C. Traeger, Department of Chemistry, La Trobe University, Bundoora, Victoria 3086, Australia. E-mail: j.traeger@ latrobe.edu.au then decompose via a bimolecular reaction between the partners, which would not have been accessible without prior bond cleavage.

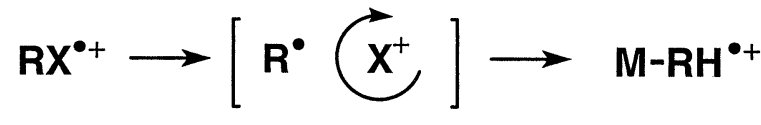

Many compounds do not produce observable parent ions. Putting electrical charge on such molecules is frequently so violent that the nascent ion has an internal energy in excess of the dissociation barrier. The difference between ion and neutral equilibrium geometries is often presumed to account for the high vibrational energy content of the parent ion, which decomposes faster than it can be detected. Ionization to produce a radical cation supplies numerous examples. However, it is also possible that dissociation might occur simultaneously with ionization. The data reported below offer evidence for such behavior. 
Saturated, tertiary aliphatic alcohols represent a class of compounds whose radical cations remain undetected by mass spectrometry. This paper looks at one of the simplest cases, a 6-carbon alcohol that has molecular symmetry. The photoionization experiments described herein show alkane elimination as the only process observable at the threshold of ionization. At higher photon energies, simple bond fissions take place. Among them, the onset of hydroxyl loss occurs at a wavelength that suggests formation of an ion pair directly from the neutral, instead of fragmentation of a molecular ion. Interactions between positive ions and expelled fragments have been examined computationally.

\section{Background}

Alkane elimination represents a class of unimolecular ion decompositions in which ion-neutral complexes intervene [2]. Eq 1 summarizes the prevailing picture of these transient intermediates: A bond in the precursor ion cleaves, but the translational kinetic energy release is not sufficient for the fragments to separate completely. Even though the fragments can recombine without an energy barrier, they persist in an electrostatically bound aggregate (the species in brackets) for a long enough time so that an ion-molecule reaction can take place between them. Within this interval, at least one of the partners can flip relative to the other about an axis perpendicular to the interfragment direction, as represented by the curved arrow in eq 1 .

Experimental studies of alkane loss show that this pathway competes with simple fission to expel an alkyl radical. The latter decomposition requires a higher internal energy. Alkane loss from ionized oxygenated molecules typically falls off precipitously once the loss of a radical becomes energetically accessible [3]. Alkane loss is therefore best studied at low internal energies. Under such conditions, flipping over one partner relative to the other (reorientation) sometimes leads to observable consequences. Experimental evidence for reorientation offers a criterion for inferring that a complex intervenes. The following instance provides a case in point.

Propane expulsion from ionized 3-methyl-2-butanol presents an example where the intermediacy of a noncovalent complex has been demonstrated by hydrogen exchange between the partners [4,5], as eqs 2 and 3 depict. The reorientation criterion is met, as shown by deuterium scrambling. In the case of the monodeuterated ion in eq 2, both labeled and unlabeled propane are ultimately expelled. The trideuterated parent ion in eq 3 loses both trideuterated and dideuterated propane. The results imply that propane forms reversibly within the complex and that the hydrocarbon can reorient so as to interchange the positions of $\mathrm{H}$ and $\mathrm{D}$.
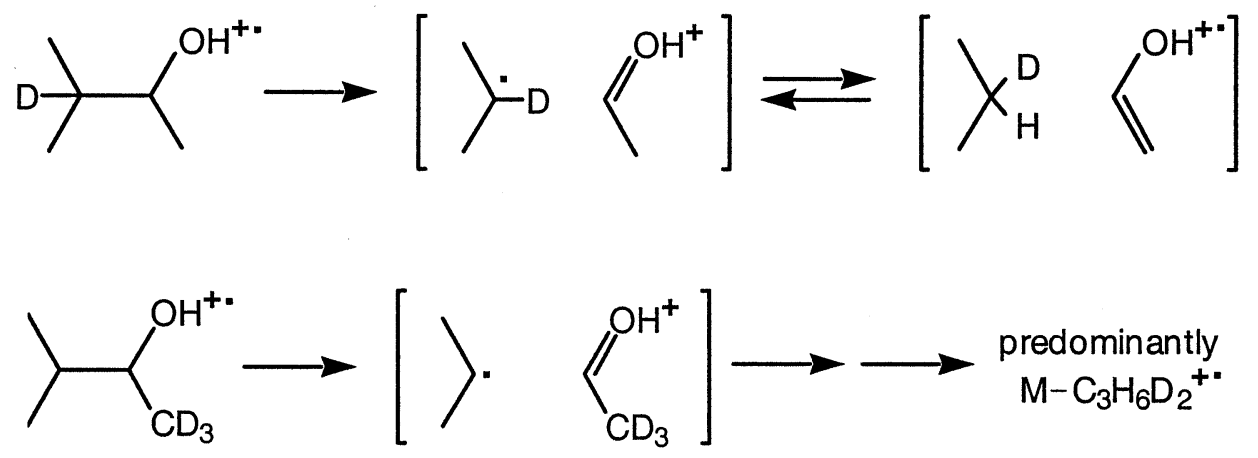

The parent ions in eqs 2 and 3 are observed in the EI mass spectrum, and their metastable ion decompositions have been examined. The $\mathrm{C}-\mathrm{H}$ bond dissociation energies of the methyl group of protonated acetaldehyde and of the methylene group of propane happen to have values very close to one another, making the interconversion of the two complexes in eq 2 nearly thermoneutral. Consequently, as noted above, each of the deuterated 3-methyl-2-butanols in eqs 2 and 3 expels a distribution of propane isotopomers.

What happens if the protonated carbonyl compound in the complex comes from acetone rather than acetaldehyde? The methyl $\mathrm{C}-\mathrm{H}$ bond dissociation energy of the protonated ketone is $3 \mathrm{~kJ} \mathrm{~mol}^{-1}$ lower than that of the protonated aldehyde. [Based on the $91 \mathrm{~kJ} \mathrm{~mol}^{-1}$ difference in heats of formation of the protonated carbonyl compounds [16] and the reported 94.0 $\pm 1.5 \mathrm{~kJ}$ $\mathrm{mol}^{-1}$ difference in heats of formation of the corresponding enol radical cations [18].] Does the exothermicity of the atom abstraction suppress reversible hydrogen transposition between the partners? If so, experimental evidence for reorientation will be hard to obtain. Does alkane elimination still take place via an ion-neutral complex? In other words, is there an intermediate that satisfies the reorientation criterion?

Responding to these questions requires an examination of tertiary alcohols. Since, as noted above, parent radical cations of these compounds have never been observed, metastable ion dissociations of the molecular ions cannot be probed. Instead, their chemistry must be investigated near the onset of ionization. 


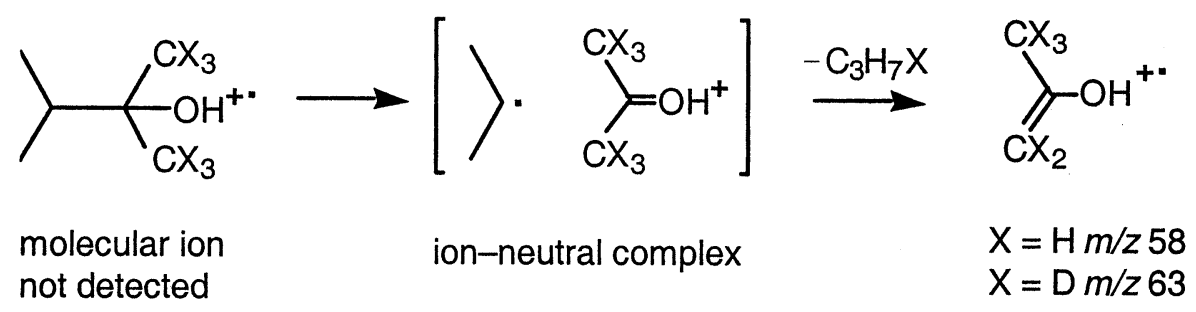

The present work looks at the threshold behavior of thexyl alcohol (2,3-dimethyl-2-butanol) and reveals that propane elimination does indeed proceed without detectable hydrogen transposition, as eq 4 summarizes. Hence, the experimental data cannot directly address the question whether reorientation takes place before dissociation. Yet the photoionization experiments reported herein do show that propane loss operates to the exclusion of competing pathways near the onset of ion production. The energy gap between this threshold and the appearance energy for loss of isopropyl radical permits an assessment of the energy content of the ion prior to alkane loss. From these data a theoretical picture can be sketched of the interaction between partners within the complex. The results of ab initio calculations indicate that the transient intermediate drawn in eq 4 does possess enough internal energy for the charged partner to flip relative to the isopropyl radical, thus predicting that the reorientation criterion should be satisfied.

\section{Experimental}

2,3-Dimethyl-2-butanol (thexyl alcohol) was purchased from Aldrich Chemical Co. (Milwaukee, MI) and used without further purification. The $1,1,1,1^{\prime}, 1^{\prime}, 1^{\prime}-d_{6}$ analogue of thexyl alcohol, $\left(\mathrm{CH}_{3}\right)_{2} \mathrm{CHC}\left(\mathrm{CD}_{3}\right)_{2} \mathrm{OH}$ (designated below simply as $d_{6}$ ), was prepared by addition of isobutyryl chloride (Aldrich) to excess methyl- $d_{3}$ magnesium iodide in ether (Aldrich), followed by two successive distillations.

Photoionization efficiency (PIE) curves were measured on an apparatus that has been described elsewhere $[6,7]$. The source of a microcomputer-controlled magnetic sector mass spectrometer makes use of the hydrogen pseudocontinuum and a Seya-Namioka monochromator equipped with a holographically ruled diffraction grating. Resolution of the monochromator was fixed at $0.135 \mathrm{~nm}$, with the threshold region data internally calibrated to better than $0.001 \mathrm{eV}$ using reference spectral peaks at 128.66 and $134.52 \mathrm{~nm}(9.6364$ and $9.2166 \mathrm{eV})$. A Philips Photonics X919BL channeltron (Slatersville, RI) was used for the ion counting and an EMI 9789B photomultiplier was used to monitor the photon intensity. Data acquisition was performed with a $350 \mathrm{MHz}$ Macintosh B\&W G3 computer operating with LabVIEW 6.1 (National Instruments, Austin, TX) under OS 9.2.2. A National Instruments PCI-6601 counter/timer board provided the digital interface between the computer and the mass spectrometer. All experiments were performed at ambient temperature with sample pressures of $10^{-3} \mathrm{~Pa}$ in the ion-source region.

The $298 \mathrm{~K}$ appearance energies (AEs) were derived from a simple linear least squares extrapolation of the PIE curves in the threshold region. First differential PIE curves were obtained using the program HORIZON (Star Blue Software Inc., Yale University, CT), with a 10-point Fourier transform filter smoothing applied to the threshold data and a 20-point smoothing for the extended energy range experiments. Such curves provide the relative ion abundances, or rates of reaction, as a function of molecular ion internal energy (equal to the difference between the photon energy and the adiabatic ionization energy) [8]. The experimental data for the $\mathrm{m} / \mathrm{z} 59$ ion from thexyl alcohol were analytically corrected for the ${ }^{13} \mathrm{C}$ contribution from the adjacent $m / z 58$ ion. A similar correction was not required for the corresponding deuterated thexyl alcohol fragment ion data.

ab initio and DFT calculations were performed using GAUSSIAN '98 (Gaussian Inc., Pittsburgh, PA) [9]. Corrections for basis set superposition error were estimated by means of counterpoise. Zero-point energies were calculated from normal modes for B3LYP/6$311 \mathrm{G}^{* *}$ geometries. Topological analyses of electron densities were performed using the Atoms in Molecules approach [10] by means of the AIM2000 program (SBK-SOFTWARE, Bielefeld, Germany) on wavefunctions from optimized geometries. Theoretical bond orders $n$ were calculated from electron densities $\rho$ at bond critical points [10]. Because the conventional parameterization for $n, n=\mathrm{e}^{\mathrm{A}(\rho-\mathrm{B})}$, does not give a bond order of zero for $\rho=0$, a variant expression was used, $n=\mathrm{e}^{\mathrm{A}(\rho-\mathrm{B})}-\mathrm{e}^{-\mathrm{AB}}$, with $\mathrm{A}$ and $\mathrm{B}$ chosen to give bond orders of $n=1,2$, and 3 for staggered ethane, ethylene, and acetylene, respectively. The best fit for B3LYP/6-311G ${ }^{* *}$ electron densities gives $\mathrm{A}=5.0 \pm$ 0.1 and $\mathrm{B}=0.164 \pm 0.003$ and for $\mathrm{MP} 2 / 6-311 \mathrm{G}^{* *}$ electron densities $\mathrm{A}=6.15 \pm 0.15$ and $\mathrm{B}=0.197 \pm$ 0.003 . For $\mathrm{C}-\mathrm{O}$ bonds, these constants were chosen so that the bonds in neutral thexyl alcohol and acetone have bonds orders of $n=1$ and 2, respectively, giving $\mathrm{A}=2.50$ and $\mathrm{B}=-0.0659$ for B3LYP electron densities and $A=2.62$ and $B=-0.0345$ for MP2/6-311G** electron densities. RRKM calculations were performed by means of a direct count algorithm, using unscaled B3LYP/6-311G** harmonic frequencies. 

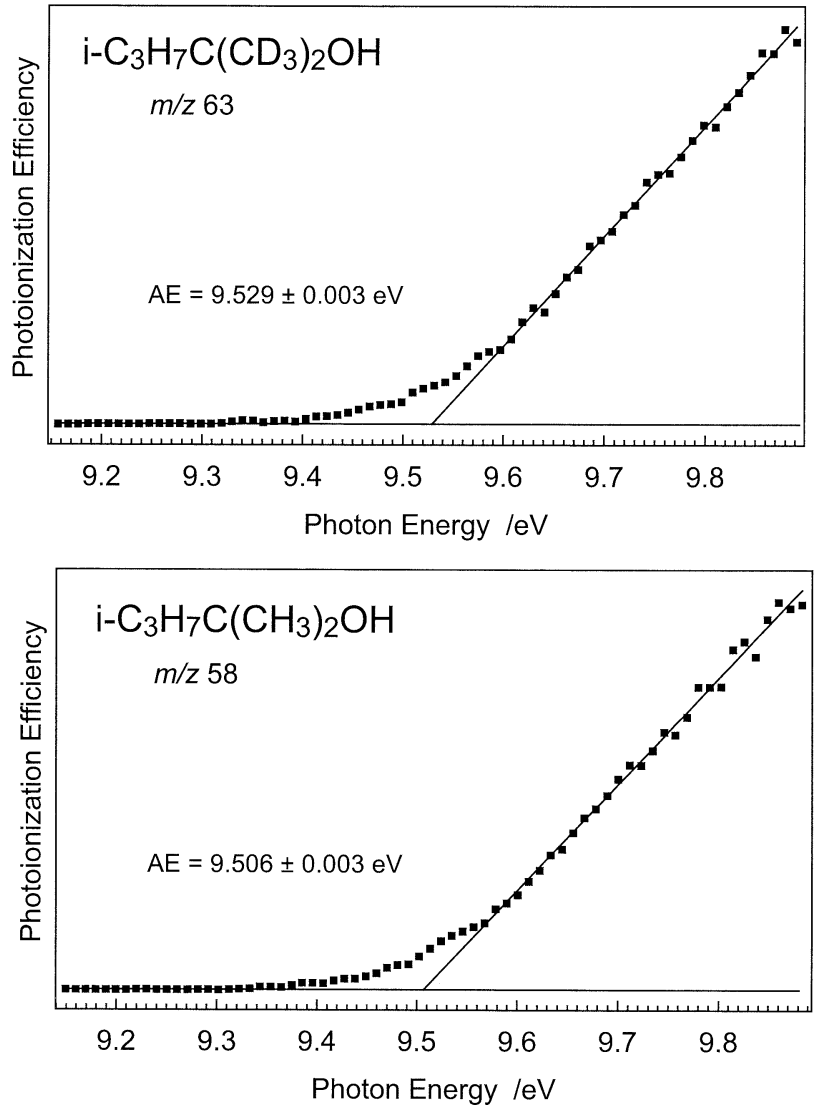

Figure 1. Threshold PIE curves for the loss of propane from ionized thexyl alcohol and its $d_{6}$ analogue. The indicated $0.003 \mathrm{eV}$ errors represent the standard deviation for a linear least squares fit to the data points above a photon energy of $9.6 \mathrm{eV}$.

\section{Results}

Thexyl alcohol does not exhibit a molecular ion. The only ion observed at the photoionization threshold is $\mathrm{m} / \mathrm{z} 58$ from the unlabeled alcohol and $\mathrm{m} / \mathrm{z} 63$ from the $d_{6}$-alcohol. These ions correspond to loss of propane and propane- $d_{1}$, respectively. As Figure 1 illustrates, the appearance energy of unlabeled thexyl alcohol occurs at photon energies $0.023 \pm 0.004 \mathrm{eV}$ below that for the deuterated alcohol. Because of the poorly defined onsets and extended curvature in the threshold regions for the PIE curves corresponding to loss of an isopropyl or a methyl radical, it is difficult to obtain a quantitative estimate of their appearance energies relative to that for loss of propane. To overcome this we have plotted first differential PIE curves in which the data have been normalized to produce essentially parallel plots. Figure 2a shows this for thexyl alcohol- $d_{6}$. The energy difference between the $\mathrm{m} / \mathrm{z} 63$ and $\mathrm{m} / \mathrm{z} 65$ curves is $0.156 \pm$ $0.002 \mathrm{eV}$, obtained from a set of 15 differences measured at intervals of $5 \%$ between ordinate values of 20 and $90 \%$. The corresponding difference between the $\mathrm{m} / \mathrm{z} 63$ and 90 curves is $0.232 \pm 0.003 \mathrm{eV}$. Figure $2 \mathrm{~b}$ shows a similar first differential plot for the undeuterated thexyl alcohol. The energy differences for the $m / z 59$,
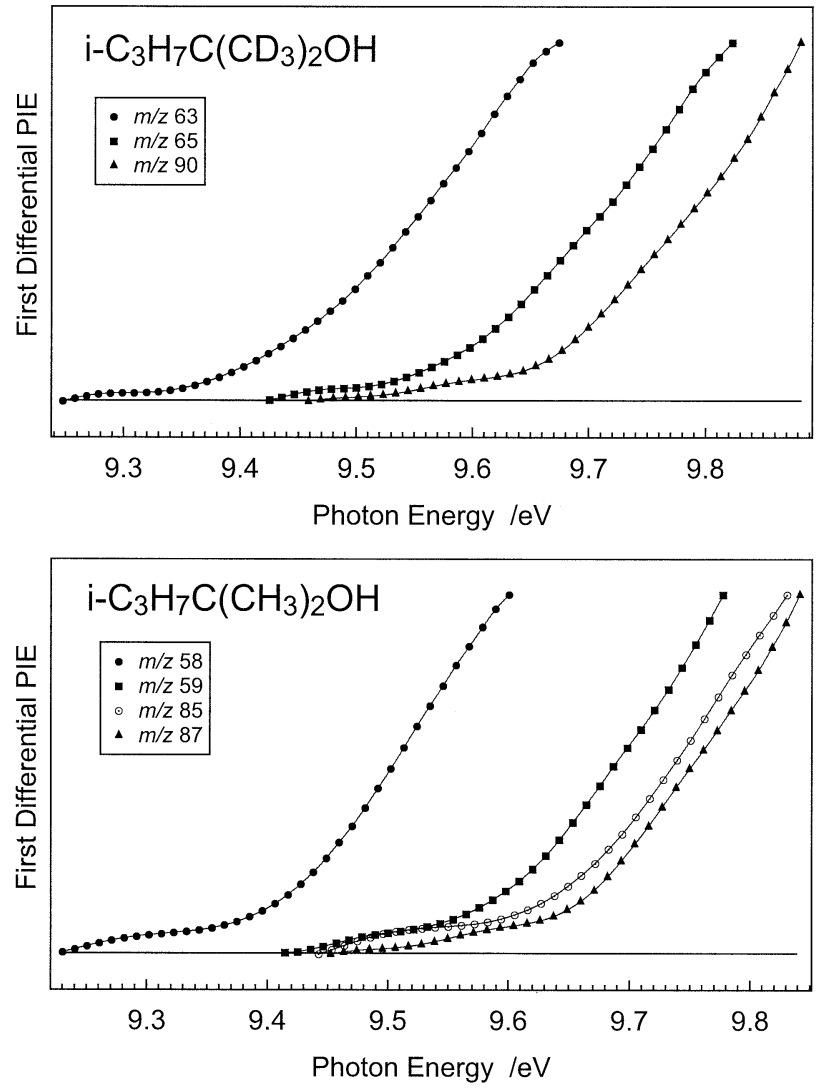

Figure 2. (a) Normalized threshold first differential PIE curves for the loss of $\mathrm{C}_{3} \mathrm{H}_{7} \mathrm{D}(\mathrm{m} / \mathrm{z} 63), \mathrm{C}_{3} \mathrm{H}_{7}(\mathrm{~m} / \mathrm{z} 65)$ and $\mathrm{CD}_{3}(\mathrm{~m} / \mathrm{z} 90)$ from thexyl alcohol- $d_{6}$. (b) Normalized threshold first differential PIE curves for the loss of $\mathrm{C}_{3} \mathrm{H}_{8}(\mathrm{~m} / \mathrm{z} 58), \mathrm{C}_{3} \mathrm{H}_{7}(\mathrm{~m} / \mathrm{z} 59), \mathrm{OH}(\mathrm{m} / \mathrm{z}$ 85) and $\mathrm{CH}_{3}(\mathrm{~m} / \mathrm{z}$ 87) from thexyl alcohol. The $\mathrm{m} / \mathrm{z} 59$ curve has been corrected for the $3.3 \%{ }^{13} \mathrm{C}$ contribution from the adjacent $\mathrm{m} / \mathrm{z} 58$ ion.

85 , and 87 curves relative to the $\mathrm{m} / \mathrm{z} 58$ curve are 0.184 $\pm 0.003 \mathrm{eV}, 0.231 \pm 0.003 \mathrm{eV}$, and $0.249 \pm 0.003 \mathrm{eV}$, respectively.

From the heats of formation listed in the Appendix for thexyl alcohol, ionized acetone enol and propane, the $298 \mathrm{~K}$ thermochemical threshold for eq 4 is calculated to be $904.0 \pm 1.0 \mathrm{~kJ} \mathrm{~mol}^{-1}$. The observed appearance energy of $9.506 \pm 0.003 \mathrm{eV}\left(917.2 \pm 0.3 \mathrm{~kJ} \mathrm{~mol}^{-1}\right)$ indicates the presence of an excess internal energy of $13.2 \pm 1.0 \mathrm{~kJ} \mathrm{~mol}^{-1}$ at threshold [using the eq [19] $\mathrm{AE}_{298}=\Delta \mathrm{H}_{\mathrm{f}, 298}^{\circ}\left(\mathrm{CH}_{3} \mathrm{C}(\mathrm{OH}) \mathrm{CH}_{2}^{+\cdot}\right)+\Delta \mathrm{H}_{\mathrm{f}, 298}^{\circ}\left(\mathrm{C}_{3} \mathrm{H}_{8}\right)-$ $\Delta \mathrm{H}_{\mathrm{f}, 298}^{\circ}$ (thexyl alcohol) $-\Delta \mathrm{H}_{\text {corr }}$, where $\Delta \mathrm{H}_{\text {cor }}$ is calculated to be $24.9 \mathrm{~kJ} \mathrm{~mol}^{-1}$ ].

Propane expulsion drops off at internal energies where alkyl radical loss becomes prominent. Figure 3 summarizes this competition. Similar behavior has been seen in alkane losses in photoionization studies of other oxygenated molecules [2]. Apart from a small shift in energy, there is no significant difference between the first differential PIE curves for the deuterated and undeuterated alcohols, with the same broad structural features present in both. Methane loss is not detected. 

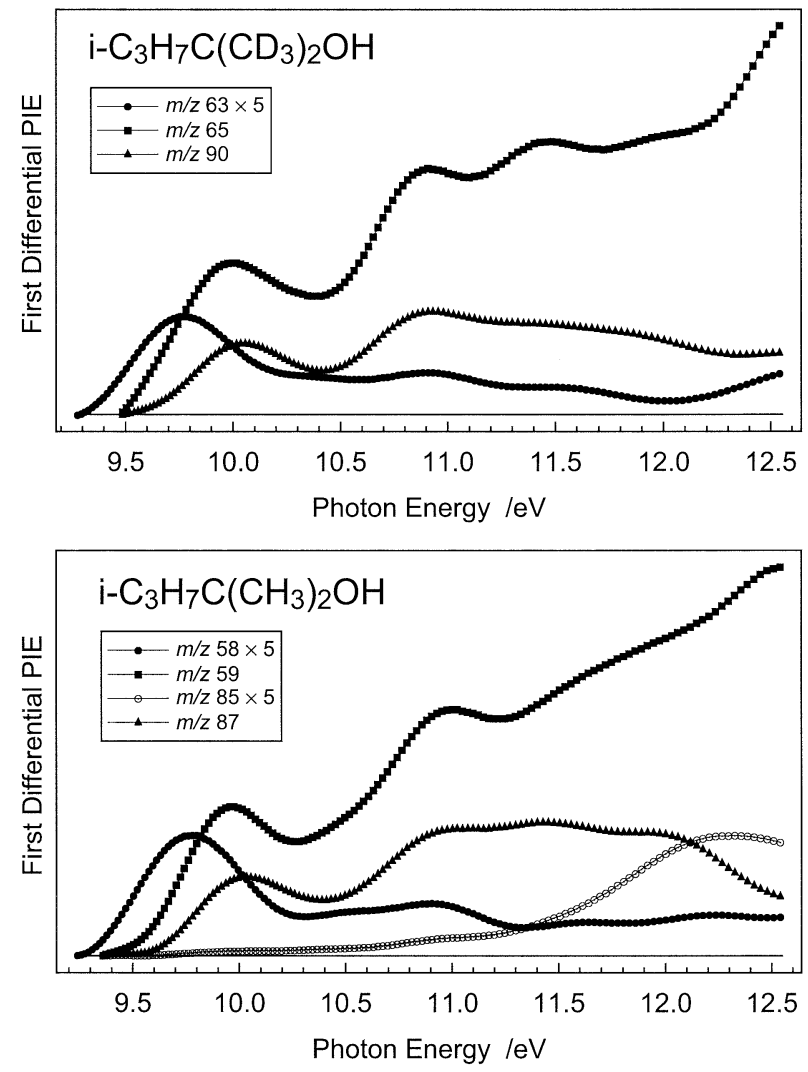

Figure 3. (a) Relative first differential PIE curves for the loss of $\mathrm{C}_{3} \mathrm{H}_{7} \mathrm{D}(\mathrm{m} / \mathrm{z} 63), \mathrm{C}_{3} \mathrm{H}_{7}\left(\mathrm{~m} / \mathrm{z}\right.$ 65) and $\mathrm{CD}_{3}(\mathrm{~m} / \mathrm{z}$ 90) from thexyl alcohol- $d_{6}$. (b) Relative first differential PIE curves for the loss of $\mathrm{C}_{3} \mathrm{H}_{8}(m / z 58), \mathrm{C}_{3} \mathrm{H}_{7}(m / z 59), \mathrm{OH}\left(m / z\right.$ 85) and $\mathrm{CH}_{3}(m / z$ 87) from thexyl alcohol.

\section{Computational}

Calculations were performed in order to assess ion geometries and energetics, as well as to explore the interactions between fragments in the course of dissociation. Neutral thexyl alcohol (illustrated in Scheme 1) has two low lying conformations, one with $C_{s}$ symmetry, in which all the bonds are antiperiplanar, and the other with $C_{1}$ symmetry, having the same geometry of the carbon skeleton, but with the $\mathrm{OH}$ rotated around the $\mathrm{C}-\mathrm{O}$, so that the hydroxylic hydrogen is synclinal with the isopropyl group. Geometry optimization at the MP2/6-311G** level shows the $C_{s}$ structure to be slightly lower in energy. MP2/6-311G $\mathrm{G}^{* *}$ calculations predict a dihedral angle of $71.5^{\circ}$ between the central $\mathrm{C}-\mathrm{C}$ bond and the $\mathrm{O}-\mathrm{H}$ bond for the $\mathrm{C}_{1}$ structure.

With respect to ionized thexyl alcohol, DFT and MP2 calculations do not give complete agreement with one another. When an electron is removed from the $C_{s}$ structure, UMP2 predicts that the methyl bonds to the carbinol carbon simultaneously elongate to $1.62 \AA$. The $\mathrm{CH}_{3}$-carbinol- $-\mathrm{CH}_{3}$ bond angle shrinks to $98^{\circ}$, while the other $\mathrm{C}-\mathrm{C}-\mathrm{C}$ bond angles remain within a few degrees of tetrahedral.

By contrast, DFT predicts that constraining the ion to $C_{s}$ symmetry leads to elongation of the $\mathrm{C}-\mathrm{O}$ bond distance to $3.0 \AA$, concomitant with planarization of carbon 2. The zero-point energy difference between the $C_{s}$ neutral and the $C_{\mathrm{s}}$ ion is $1 \mathrm{~kJ} \mathrm{~mol}^{-1}$ less for thexyl alcohol- $d_{6}$ than for the undeuterated alcohol. That change is consistent with the observation that the undeuterated alcohol displays a lower threshold for ionization.

The $C_{s}$ ion does not represent the most stable geometry. If the symmetry constraint is relaxed, one of the $\mathrm{C}-\mathrm{C}$ bonds elongates. The most stable molecular ion structure results from elongation of the $\mathrm{C}_{2}-\mathrm{C}_{3}$ bond to $>2 \AA$, which makes the ion look like an isopropyl radical loosely bound to protonated acetone. DFT calculations predict that this $C_{1}$ ion structure is $90 \mathrm{~kJ} \mathrm{~mol}^{-1}$ more stable than the $C_{s}$ ion. The extent of $C_{2}-C_{3}$ elongation depends on the computational level, as shown in Table 1. For both the DFT and UMP2optimized geometries the $\mathrm{C}_{2}-\mathrm{C}_{3}$ axis makes a $120^{\circ}$ angle with the $\mathrm{C}-\mathrm{C}-\mathrm{C}$ plane of the isopropyl, as compared with $130^{\circ}$ in the neutral molecule. The $\mathrm{C}-\mathrm{C}-\mathrm{C}$ plane of the isopropyl makes the same angle with the $\mathrm{C}-\mathrm{C}-\mathrm{C}$ plane of the protonated acetone at both levels of computation $\left(9^{\circ}\right.$ at $\mathrm{UMP} 2$ and $8^{\circ}$ at DFT, as compared with $1^{\circ}$ in the neutral alcohol).

Table 1 summarizes Atoms in Molecules determinations of the $\mathrm{C}_{2}-\mathrm{C}_{3}$ bond order at various levels for the geometry-optimized ion. When the ion geometry is constrained to that of the neutral, this bond order has a value of $n=1.0$. Table 1 does not include $\mathrm{C}-\mathrm{O}$ bond orders, which change in the opposite direction when the ion geometry is optimized. For the neutral, the $\mathrm{C}_{2}-\mathrm{O}$ bond order is close to 1 . When the ion is constrained to the neutral geometry its $\mathrm{C}_{2}-\mathrm{O}$ bond order decreases (to

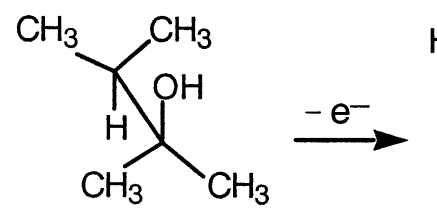

thexyl alcohol

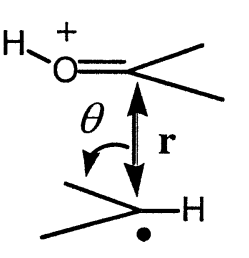

preferred ion structure

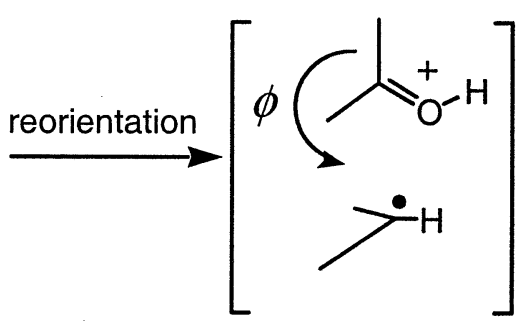

A

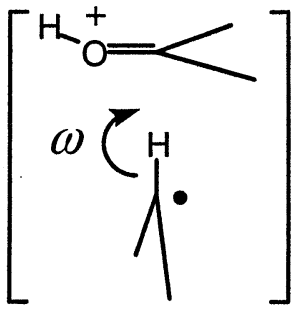

B 
Table 1. $C_{2}-C_{3}$ distance $(r), C_{2}-C_{3}$-methyl bond angles $(\theta)$, electron density at the bond critical point $(\rho)$ and the corresponding $\mathrm{C}_{2}-\mathrm{C}_{3}$ bond order $(n)$, and counterpoise-corrected dissociation energy of the $\mathrm{C}_{2}$-isopropyl bond for ionized 2,3-dimethyl-2-butanol optimized at various levels using the $6-311 \mathrm{G}^{* *}$ basis set. Uncertainties in $n$ reflect the quality of fit of CC single, double, and triple bonds to the expression $n=\mathrm{e}^{\mathrm{A}(\rho-\mathrm{B})}-\mathrm{e}^{-\mathrm{AB}}$

\begin{tabular}{lccccc}
\hline Level & $\mathbf{r}(\AA)$ & $\theta$ & $\rho$ at bcp (a.u.) & Bond order $(n)$ & $\left.D_{e}(\mathrm{~kJ} \mathrm{~mol})^{-1}\right)$ \\
\hline \hline UHF & 3.265 & $97^{\circ}, 103^{\circ}$ & 0.03495 & $0.070 \pm 0.007$ & 18.3 \\
B3LYP & 2.403 & $103^{\circ}$ & 0.03614 & $0.087 \pm 0.0008$ & 50.3 \\
UMP2 & 2.076 & $105^{\circ}$ & 0.06787 & $0.154 \pm 0.0025$ & 51.5 \\
\hline
\end{tabular}

$n=0.94$ at B3LYP; $n=0.86$ at UMP2), but when the ion geometry is optimized the $\mathrm{C}_{2}-\mathrm{O}$ bond order increases (to $n=1.41$ at B3LYP; 1.35 at UMP2), as compared with the higher $\mathrm{C}_{2}-\mathrm{O}$ bond order of $\mathrm{O}$-protonated acetone $(n$ $=1.61$ at B3LYP; $n=1.58$ at MP2).

The two fragments in the molecular ion, i.e., isopropyl radical and protonated acetone $\left(\mathrm{Me}_{2} \mathrm{C}=\mathrm{OH}^{+}\right)$, are only slightly pyramidalized; the sum of the three angles about the central carbon of the isopropyl radical is $353^{\circ}$ at DFT and $350^{\circ}$ at UMP2, while the sum of the three angles about the central carbon of the $\mathrm{Me}_{2} \mathrm{C}=\mathrm{OH}^{+}$is $354^{\circ}$ at DFT and $349^{\circ}$ at UMP2. The $\mathrm{C}_{2}-\mathrm{C}_{3}$ axis makes nearly a right angle with the central $\mathrm{CH}$ bond of the isopropyl $\left(89^{\circ}\right.$ at DFT, $92^{\circ}$ at UMP2), while (as Table 1 summarizes) the angles $\theta$ made by the $C_{2}-C_{3}$ axis with the methyl- $\mathrm{C}_{3}$ bonds of the isopropyl are both the same $\left(103^{\circ}\right.$ at DFT and $105^{\circ}$ at UMP2).

Despite the differences in geometry between the DFT and MP2 optimizations, their electronic energies of dissociation $\left(D_{e}\right)$ are nearly the same. The additional contribution from zero-point energy differences reduces the bond dissociation energy to $\mathrm{D}_{0}=38 \mathrm{~kJ} \mathrm{~mol}^{-1}$.

Calculated thermochemical thresholds (MP2 + BSSE, with DFT zero-point energies) give consistently lower values than those inferred from published heats of formation (Table 2). As will be discussed below, these bear little resemblance to the measured photoionization appearance energies. Nevertheless, the quality of agreement between calculated and published thermochemistry for oxygen-containing ions (a mean discrepancy of $14 \mathrm{~kJ} \mathrm{~mol}^{-1}$ ) is adequate to justify this level of computation for looking at geometry distortions.

The consequences of altering bond length have been investigated. A DFT harmonic normal modes calculation on the B3LYP optimized geometry gives a $C_{2}-C_{3}$ bond stretching frequency of $126 \mathrm{~cm}^{-1}$. This value reflects the force constant for small amplitude contrac- tion as well as extension. To calculate the force constant simply for large amplitude stretching of the $C_{2}-C_{3}$ bond, the effect of elongating the $C_{2}-C_{3}$ distance $\mathbf{r}$ by 1 $\AA$ was computed at UMP2, which raises the electronic energy (including BSSE correction) by $19 \mathrm{~kJ} \mathrm{~mol}^{-1}$. The Hooke's law constant thus has a value of 0.065 mdyne $\AA^{-1}$, corresponding to a harmonic frequency of $67 \mathrm{~cm}^{-1}$ for a large amplitude $C_{2}-C_{3}$ stretch. Proceeding from $\mathbf{r}$ $=3.07 \AA$ to infinity then costs an additional $32 \mathrm{~kJ} \mathrm{~mol}^{-1}$. For comparison, using the calculated exact polarizability of an isopropyl radical along the direction perpendicular to its $\mathrm{C}-\mathrm{C}-\mathrm{C}$ plane $\left(\alpha=4.5 \AA^{3}\right)$ predicts an energetic cost of $35 \mathrm{~kJ} \mathrm{~mol}^{-1}$, based on the expression $\Delta \mathrm{E}=-\alpha \mathrm{e}^{2} / 2 \mathrm{r}^{4}$. Thus, a bond extension of $1 \AA$ brings ionized thexyl alcohol into a regime where ion-induced dipole attraction accounts for most of the binding energy.

As noted above, when ionized thexyl alcohol is constrained to $C_{s}$ symmetry, B3LYP shows that the $\mathrm{C}-\mathrm{O}$ bond length lengthens by $1.55 \AA$. The DFT-calculated electronic energy difference between the neutral and the ion is 10.21 $\mathrm{eV}$ (as compared to $10.41 \mathrm{eV}$ at MP2) when the geometry is constrained to the neutral geometry. No attempt was made to compensate for BSSE in these estimates of the vertical ionization energy. Since the ion in that geometry does not correspond to a stationary state, zero-point energy contributions were also not taken into account. The MP2 energy difference between neutral thexyl alcohol and the optimized geometry of the ion, including zero-point energies, is $867.0 \mathrm{~kJ} \mathrm{~mol}^{-1}$ which corresponds to an adiabatic ionization energy of $8.99 \mathrm{eV}$.

It is of interest to consider changes in electrical charge as a function of geometry. Using DFT, an Atoms in Molecules topological analysis places a net charge of -0.52 on the hydroxyl in neutral thexyl alcohol. Vertical ionization gives a structure in which the charge on the hydroxyl is still negative, -0.14 . Then, when the $C_{s}$ ion geometry is optimized, the charge on the hydroxyl

Table 2. Energetics $\left(\mathrm{kJ} \mathrm{mol}^{-1}\right)$ for fragments, including MP2 total energies (uncorrected for BSSE) relative to neutral thexyl alcohol (-311.431554 a.u.), unscaled B3LYP zero-point energies (neutral thexyl alcohol ZPE $=503.3 \mathrm{~kJ} \mathrm{~mol}^{-1}$ ), $0 \mathrm{~K}$ thermochemical thresholds calculated from data in the Appendix, and photoionization onsets from data in Figures 1 and $2 \mathrm{~b}$ corrected to $0 \mathrm{~K}$

\begin{tabular}{|c|c|c|c|c|c|}
\hline \multirow[b]{2}{*}{ Products } & \multirow{2}{*}{$\begin{array}{l}\text { Total Energy } \\
\text { (hartrees) }\end{array}$} & \multirow[b]{2}{*}{ ZPE } & \multicolumn{3}{|c|}{ Thermochemistry } \\
\hline & & & Theory & Literature & PI onset \\
\hline $\mathrm{CH}_{3} \mathrm{C}(\mathrm{OH}) \mathrm{CH}_{2}^{+\cdot}+\mathrm{C}_{3} \mathrm{H}_{8}$ & 0.353092 & 489.4 & 914 & 925 & 938 \\
\hline$\left(\mathrm{CH}_{3}\right)_{2} \mathrm{COH}^{+}+2-\mathrm{C}_{3} \mathrm{H}_{7}$ & 0.361785 & 481.5 & 928 & 943 & 956 \\
\hline $2-\mathrm{C}_{3} \mathrm{H}_{7} \mathrm{C}\left(\mathrm{CH}_{3}\right)_{2}^{+}+\mathrm{OH}$ & 0.401132 & 478.4 & 1006 & 1031 & 961 \\
\hline $2-\mathrm{C}_{3} \mathrm{H}_{7} \mathrm{C}\left(\mathrm{CH}_{3}\right)=\mathrm{OH}^{+}+\mathrm{CH}_{3}$ & 0.356752 & 479.5 & 913 & 929 & 962 \\
\hline
\end{tabular}


becomes essentially zero. These variations in charge contrast with the slight effect that bond lengthening has on the neutral alcohol (at a C-O bond length of $3.0 \AA$ the charge on the hydroxyl is -0.55 , and extension by another $0.5 \AA$ increases the charge to -0.57 ).

Distortions by large amplitude bending motions have greater relevance to the question as to whether ionized thexyl alcohol behaves as an ion-neutral complex. Two approaches were used to assess the barriers to reorientation. One approach has been to optimize geometries with fixed angles $\phi$ and $\omega$, as represented by Structures A and B in Scheme 1. For Structure A, the geometry was first optimized with the $C_{1}-C_{2}-C_{3}$ angle $\phi$ fixed at $180^{\circ}$. This gives electronic energy barriers of $28 \mathrm{~kJ} \mathrm{~mol}^{-1}$ (DFT) and $36 \mathrm{~kJ} \mathrm{~mol}^{-1}$ (UMP2).

The same type of approach to reorientation of the isopropyl fixes the $\mathrm{C}_{2}-\mathrm{H}-\mathrm{C}_{3}$ angle $\omega$ at $180^{\circ}$, as Structure $\mathbf{B}$ illustrates. This gives an electronic energy barrier of $42 \mathrm{~kJ} \mathrm{~mol}^{-1}$ (UMP2), placing the barrier for reorientation of the isopropyl radical above the thermodynamic threshold energy for propane loss.

The second approach was to optimize the transition state for Structure A. At the DFT level this raised the electronic energy barrier slightly to $29 \mathrm{~kJ} \mathrm{~mol}^{-1}$, and the zero-point energy difference leads to a net activation barrier $\mathrm{E}_{0}=18 \mathrm{~kJ} \mathrm{~mol}^{-1}$. In this transition state, $\mathbf{r}=4.00$ $\AA, \phi=141^{\circ}$, and the C-C-C plane of the isopropyl group makes a $66^{\circ}$ angle with the $\mathrm{C}-\mathrm{C}-\mathrm{C}$ plane of the protonated acetone. The net electric charge on the isopropyl is reduced in the transition state (to +0.24 ) relative to the charge it bears in the DFT-optimized ion geometry $(+0.35)$. At the same time, the $\mathrm{C}-\mathrm{O}$ bond order increases to $n=1.47$ (relative to $n=1.41$ in the DFT-optimized ion geometry). Since the two approaches for Structure A led to such a small change in electronic energy, no other transition state optimizations were performed.

\section{Discussion}

Orbiting phenomena occur widely in physics, when two-body problems are perturbed by other interactions. In astronomy, for instance, a surprisingly large proportion of near-Earth asteroids (estimated as high as 1 in 6) appear to be members of binary systems, and binaries occur in main belt asteroids, as well [11]. At a greater distance from the sun, binaries constitute several percent of Kuiper Belt objects, in which both partners have comparable masses [12]. Gravitational attraction holds these pairs of objects in orbit about their center of mass. In similar fashion, transient ion-neutral complexes form at the molecular scale in the gas phase, held together by electrostatic attraction.

The analogy between astronomical objects and unimolecular ion dissociations should not be taken too far, because no significant centrifugal barrier prevents the recombination of the charged and neutral partner when the parent ion is produced by photoionization of a thermalized neutral. Also, it is unclear whether the binaries seen by astronomers exhibit mutually locked rotation, whereby neither partner can rotate freely. By contrast, the presumption of unlocked rotation (reorientation) by at least one partner represents a defining characteristic of ion-neutral complexes [13].

Does the equilibrium geometry of ionized thexyl alcohol correspond to an ion-neutral complex? The computational results are equivocal, since, as Table 1 summarizes, the $C_{2}-C_{3}$ bond length $\mathbf{r}$ varies, according to the calculational level. However, the degree of residual bonding (bond order of $n=0.09$ at B3LYP; $n=0.15$ at UMP2), relative to $n=1$ for ethane, would seem to argue for retention of some degree of directed valence between the isopropyl radical and protonated acetone. Integration over atomic basins shows that the isopropyl group carries a large fraction of the positive charge $(0.35$ at B3LYP; 0.50 at UMP2), indicating that it ought not to be viewed strictly as an uncharged isopropyl radical.

From a practical standpoint, it is more relevant to inquire whether the ionized alcohol has enough internal energy to exhibit reorientation at the threshold for propane loss. Previous computational work has characterized loosely bound ions in which vibrational excitation below the dissociation threshold permits reorientation of the charged partner [14]. Ionized thexyl alcohol corresponds to such a situation. On the one hand, experimental threshold measurements and ab initio calculations combine to predict that the barrier height for flipping protonated acetone lies below the experimental ionization threshold. On the other hand, the separation between those barriers is not large.

Experimentally, the separation of the undeuterated first differential curves in Figure $2 b$ implies that onset of isopropyl radical loss onset occurs $18 \mathrm{~kJ} \mathrm{~mol}^{-1}$ above the appearance energy for propane loss, while the onset of methyl radical loss occurs $6 \mathrm{~kJ} \mathrm{~mol}^{-1}$ higher than isopropyl loss. UMP2 predicts a $14 \mathrm{~kJ} \mathrm{~mol}^{-1}$ separation between the thermodynamic thresholds for propane loss versus cleavage of isopropyl radical, but the apparent agreement between experiment and theory here may be deceptive. No molecular ion is detected, and propane loss produces the only ions seen at the onset of ionization. Therefore the onset of propane loss will represent the ionization threshold rather than a true thermochemical appearance energy.

At the internal energy corresponding to the onset of propane loss, ab initio calculations show that the cation should be able to reorient relative to its neutral partner. At B3LYP, the top of the barrier corresponding to Structure B in Scheme 1 is calculated to lie $E_{0}=26 \mathrm{~kJ}$ $\mathrm{mol}^{-1}$ above the optimized geometry of ionized thexyl alcohol. UMP2 calculations give virtually the same barrier height, $\mathrm{E}_{0}=25 \mathrm{~kJ} \mathrm{~mol}^{-1}$, but the counterpoise estimate of basis set superposition error makes a much greater contribution $\left(\triangle \mathrm{BSSE}=16.5 \mathrm{~kJ} \mathrm{~mol}^{-1}\right)$ at this level of computation. To account properly for BSSE, the $\mathrm{UMP} 2$ barrier top is gauged relative to the threshold for $\mathrm{C}_{2}-\mathrm{C}_{3}$ cleavage, which predicts $\mathrm{E}_{0}$ to be $14.5 \mathrm{~kJ} \mathrm{~mol}^{-1}$ lower than the $0 \mathrm{~K}$ threshold for expulsion of isopropyl radical. This gives an energy for the barrier top virtually 
equal to the calculated $0 \mathrm{~K}$ thermodynamic threshold for propane loss.

The photoionization experiments show onset of propane loss at an energy $13 \mathrm{~kJ} \mathrm{~mol}^{-1}$ above the empirically predicted threshold (Table 2). Therefore, the energy content of the putative thexyl alcohol radical cation at the onset of ionization can be taken to have a value $\mathrm{E}^{*}-\mathrm{E}_{0}=13 \mathrm{~kJ} \mathrm{~mol}^{-1}$ above the reorientation barrier. An RRKM calculation predicts that, once the value of $\mathrm{E}^{*}-\mathrm{E}_{0}$ exceeds $4.5 \mathrm{~kJ} \mathrm{~mol}^{-1}$, flipping protonated acetone within the complex ought to have a first-order rate constant $\mathrm{k} \geq 1 \times 10^{10} \mathrm{sec}^{-1}$. Even if the calculation overestimates $E^{*}-E_{0}$ by a factor of 3 , the charged partner should be able to turn itself over within the complex at a rate much faster than decomposition takes place. The hypothesis of a transient, highly vibrationally excited thexyl alcohol radical cation implies that there is not only sufficient internal energy to flip over the protonated acetone, but that the isopropyl radical may even be able to reorient, as well, via geometry B in Scheme $\mathbf{1}$ (angle $\omega=180^{\circ}$ ).

The appearance energy for thexyl cation is far lower than would be predicted if hydroxyl radical is ejected from a transient thexyl alcohol radical cation (Table 2). No other $\mathrm{C}_{6} \mathrm{H}_{13}^{+}$structure has a lower heat of formation than thexyl cation [15], so the appearance energy cannot be attributed to isomerization. However, hydroxyl radical has such a high electron affinity [16] that formation of a $\mathrm{C}_{6} \mathrm{H}_{13}^{+}, \mathrm{OH}^{-}$ion pair directly from the neutral alcohol would be endothermic by only $8.86 \mathrm{eV}(855.0 \mathrm{~kJ}$ $\mathrm{mol}^{-1}$ ) at $0 \mathrm{~K}$ (Appendix). There is as yet no direct evidence for anion formation, but ion pair creation does present a thermochemically accessible mechanism.

Finally, the difference between the predicted thermochemical threshold for loss of methyl radical and the observed appearance energy warrants comment. On the basis of translational kinetic energy release data from metastable ion decompositions, Hammerum and Derrick have reported several cases where $\alpha$-cleavage of methyl for amine molecular ions must encounter a reverse activation barrier [17]. If there were no reverse activation barriers for $\alpha$-cleavage of ionized thexyl alcohol, methyl loss should have had an appearance energy $14 \mathrm{~kJ} \mathrm{~mol}^{-1}$ lower than that of isopropyl loss (Table 2). Instead, the experimental appearance energy is $6 \mathrm{~kJ} \mathrm{~mol}^{-1}$ higher. This implies a reverse activation energy $\geq 20 \mathrm{~kJ} \mathrm{~mol}^{-1}$ for methyl cleavage.

\section{Conclusions}

Photoionization measurements on thexyl alcohol give appearance energies different from the expected thermodynamic thresholds. No molecular ion is observed. The data lead to the following inferences:

- The radical cation of acetone enol represents the only ion observed at threshold, which corresponds to propane expulsion from a short-lived, vibrationallyexcited molecular ion. Isotopic exchange does not occur in the course of this decomposition, but ab initio calculations support the conclusion that an ion-neutral complex intervenes as a transient intermediate.

- Formation of thexyl cation cannot arise by simple loss of hydroxyl radical from the putative molecular ion, since its appearance energy is far too low. Ion-pair production directly from a photoexcited neutral offers a testable hypothesis.

- The appearance energy for methyl loss is much higher than predicted on thermochemical grounds. The energy gap between this dissociation and isopropyl loss provides a measure of the reverse activation barrier. Further studies of tert-alkyl methyl ethers are underway.

\section{Acknowledgments}

This work was supported by NSF grant CHE0316515.

\section{Appendix}

Supplementary thermochemical data

\begin{tabular}{|c|c|c|c|}
\hline Species & \multicolumn{2}{|c|}{$\begin{array}{l}\mathrm{H}^{\circ}{ }_{298}-\mathrm{H}^{\circ}{ }_{0} \\
\left(\mathrm{~kJ} \mathrm{~mol}^{-1}\right)\end{array}$} & Reference \\
\hline C & \multicolumn{2}{|c|}{1.1} & [20] \\
\hline $\mathrm{H}_{2}$ & \multicolumn{2}{|c|}{8.5} & [20] \\
\hline $\mathrm{O}_{2}$ & \multicolumn{2}{|c|}{8.7} & [20] \\
\hline $\mathrm{OH}$ & \multicolumn{2}{|c|}{9.2} & [20] \\
\hline $\mathrm{OH}^{-}$ & \multicolumn{2}{|c|}{8.6} & [20] \\
\hline $\mathrm{CH}_{3}$ & \multicolumn{2}{|c|}{10.4} & [20] \\
\hline $2-\mathrm{C}_{3} \mathrm{H}_{7}$ & \multicolumn{2}{|c|}{15.7} & [21] \\
\hline $\mathrm{C}_{3} \mathrm{H}_{8}$ & \multicolumn{2}{|c|}{14.7} & [21] \\
\hline $\mathrm{CH}_{3} \mathrm{C}(\mathrm{OH}) \mathrm{CH}_{2}^{+\cdot}$ & \multicolumn{2}{|c|}{16.4} & [22] \\
\hline$\left(\mathrm{CH}_{3}\right)_{2} \mathrm{COH}^{+}$ & \multicolumn{2}{|c|}{16.8} & This work \\
\hline $2-\mathrm{C}_{3} \mathrm{H}_{7} \mathrm{C}\left(\mathrm{CH}_{3}\right)=\mathrm{OH}^{+}$ & \multicolumn{2}{|c|}{23.3} & This work \\
\hline $2-\mathrm{C}_{3} \mathrm{H}_{7} \mathrm{C}\left(\mathrm{CH}_{3}\right)_{2}^{+}$ & \multicolumn{2}{|c|}{25.4} & This work \\
\hline $2-\mathrm{C}_{3} \mathrm{H}_{7} \mathrm{C}\left(\mathrm{CH}_{3}\right)_{2} \mathrm{OH}$ & \multicolumn{2}{|c|}{27.3} & This work \\
\hline Species & $\begin{array}{c}\Delta \mathrm{H}_{\mathrm{f}, 298}^{\circ} \\
\left(\mathrm{kJ} \mathrm{mol}^{-1}\right)\end{array}$ & $\begin{array}{c}\Delta \mathrm{H}_{\mathrm{f}, 0}^{\circ} \\
\left(\mathrm{kJ} \mathrm{mol}^{-1}\right)\end{array}$ & Reference \\
\hline $\mathrm{OH}$ & 39.0 & 38.4 & [20] \\
\hline $\mathrm{OH}^{-}$ & -137.4 & -137.4 & [20] \\
\hline $\mathrm{CH}_{3}$ & 147.0 & 150.4 & [23] \\
\hline $2-\mathrm{C}_{3} \mathrm{H}_{7}$ & 91.5 & 108.6 & [21] \\
\hline $\mathrm{C}_{3} \mathrm{H}_{8}$ & -104.7 & -82.4 & [16] \\
\hline $\mathrm{CH}_{3} \mathrm{C}(\mathrm{OH}) \mathrm{CH}_{2}^{+\cdot}$ & 676.6 & 692.7 & [18] \\
\hline$\left(\mathrm{CH}_{3}\right)_{2} \mathrm{COH}^{+}$ & 499.5 & 519.7 & a \\
\hline $2-\mathrm{C}_{3} \mathrm{H}_{7} \mathrm{C}\left(\mathrm{CH}_{3}\right)=\mathrm{OH}^{+}$ & 431.1 & 464.0 & b \\
\hline $2-\mathrm{C}_{3} \mathrm{H}_{7} \mathrm{C}\left(\mathrm{CH}_{3}\right)_{2}^{+}$ & 645.8 & 678.0 & c \\
\hline $2-\mathrm{C}_{3} \mathrm{H}_{7} \mathrm{C}\left(\mathrm{CH}_{3}\right)_{2} \mathrm{OH}$ & -357.0 & -314.4 & [16] \\
\hline
\end{tabular}

aCalculated from $\Delta \mathrm{H}_{\mathrm{f}, 298}^{\circ}\left(\mathrm{CH}_{3} \mathrm{COCH}_{3}\right)=-218.5 \mathrm{~kJ} \mathrm{~mol}^{-1}$, $\Delta \mathrm{H}_{\mathrm{f}, 298}^{\circ}\left(\mathrm{H}^{+}\right)=1530 . \mathrm{kJ} \mathrm{mol}^{-1}$, and $\mathrm{PA}_{298}\left(\mathrm{CH}_{3} \mathrm{COCH}_{3}\right)=$ $812.0 \mathrm{~kJ} \mathrm{~mol}^{-1}$ [16].]

${ }^{\mathrm{b} C}$ Calculated from $\Delta \mathrm{H}_{\mathrm{f}, 298}^{\circ}\left(2-\mathrm{C}_{3} \mathrm{H}_{7} \mathrm{COCH}_{3}\right)=-262.6 \mathrm{~kJ}$ $\mathrm{mol}^{-1}, \Delta \mathrm{H}^{\circ}{ }_{\mathrm{f}, 298}\left(\mathrm{H}^{+}\right)=1530.0 \mathrm{~kJ} \mathrm{~mol}^{-1}$, and $\mathrm{PA}_{298}$ $\left.\mathrm{C}_{3} \mathrm{H}_{7} \mathrm{COCH}_{3}\right)^{2}=836.3 \mathrm{~kJ} \mathrm{~mol}^{-1}$ [16].]

'From $\Delta \mathrm{H}_{\mathrm{f}, 298}^{\circ}\left(2-\mathrm{C}_{3} \mathrm{H}_{7} \mathrm{C}\left(\mathrm{CH}_{3}\right)_{2}^{+}\right)=-217.3 \mathrm{~kJ} \mathrm{~mol}^{-1}$ [24], corrected for $\Delta \mathrm{H}_{\mathrm{f}, 298}^{\circ}\left(\right.$ tert- $\left.\mathrm{C}_{4} \mathrm{H}_{9}^{+}\right)=711.5 \mathrm{~kJ} \mathrm{~mol}^{-1}$ [21] rather than $693.7 \mathrm{~kJ} \mathrm{~mol}^{-1}$ [24].]

\section{References}

1. McLafferty, F. W.; Turecek, F. Interpretation of Mass Spectra; 4th Edition; University Science Books: Sausalito, CA, 1993. 
2. (a) Morton, T. H. Gas Phase Analogs of Solvolysis Reactions. Tetrahedron 1982, 38, 3195-3243. (b) McAdoo, D. J. Ion-Neutral Complexes in Unimolecular Decompositions. Mass Spectrom. Rev. 1988, 7, 363-393. (c) McAdoo, D. J.; Bowen, R. D. Alkane Eliminations from Ions in the Gas Phase. Eur. Mass Spectrom. 1999, 5, 389-409.

3. (a) Traeger, J. C.; Hudson, C. E.; McAdoo, D. J. Nonspecific Hydrogen Abstractions in Alkane Eliminations from Ionized Ketones. Further Evidence that Alkane Eliminations are IonNeutral Complex-Mediated. Int. J. Mass Spectrom. Ion Processes 1988, 82, 101-109. (b) Traeger, J. C.; Hudson, C. E.; McAdoo, D. J. Alkane Eliminations from Ionized Ketones in the Gas Phase: Dependence of Ion-Neutral Complex-Mediated Decompositions on the Properties of the Ionic and Neutral Partners. J. Phys. Chem. 1988, 92, 1519-1523. (c) McAdoo, D. J.; Traeger, J. C.; Hudson, C. E.; Griffin, L. L. Decompositions of Ionized Isopropyl Methyl Ether: Complex-Mediated and Direct Processes in Unimolecular Dissociations. J. Phys. Chem. 1988, 92, 1524-1530. (d) Traeger, J. C.; Hudson, C. E.; McAdoo, D. J. Energy Dependence of Ion-Induced Dipole Complex Mediated Alkane Eliminations from Ionized Ethers. J. Phys. Chem. 1990, 94, 5714-5717. (e) McAdoo, D. J.; Hudson, C. E.; Traeger, J. C.; Grosse, A.; Griffin, L. L. Size Effects in IonNeutral Complex-Mediated Alkane Eliminations from Ionized Aliphatic Ethers. J. Am. Soc. Mass Spectrom. 1991, 2, 261-269.

4. Hammerum, S.; Audier, H. E. Experimental Verification of the Intermediacy and Interconversion of Ion-Neutral Complexes as Radical Cations Dissociate. J. Chem. Soc. Chem. Commun. 1988, 860-861.

5. George, M.; Holmes, J. L. Intermediate Ion Structures in the Fragmentation of Metastable 3-Methylbutan-2-ol Radical Cations. Org. Mass Spectrom. 1990, 25, 605-608.

6. Traeger, J. C.; McLoughlin, R. G. A Photoionization Study of the Energetics of the $\mathrm{C}_{7} \mathrm{H}_{7}^{+}$Ion formed from $\mathrm{C}_{7} \mathrm{H}_{8}$ Precursors. Int. J. Mass Spectrom. Ion Phys. 1978, 27, 319-333.

7. Traeger, J. C. A Study of the Allyl Cation Thermochemistry by Photoionization Mass Spectrometry. Int. J. Mass Spectrom. Ion Processes 1984, 58, 259-271.

8. Hurzeler, H.; Inghram, M. G.; Morrison, J. D. Photon Impact Studies of Molecules with a Mass Spectrometer. J. Chem. Phys. 1958, 28, 76-82.

9. Frisch, M. J.; Trucks, G. W.; Schlegel, H. B.; Scuseria, G. E.; Robb, M. A.; Cheeseman, J. R.; Zakrzewski, V. G.; Montgomery, J. A.; Stratmann, R. E.; Burant, J. C.; Dapprich, S.; Millam, J. M.; Daniels, A. D.; Kudin, K. N.; Strain, M. C.; Farkas, O.; Tomasi, J.; Barone, V.; Cossi, M.; Cammi, R.; Mennucci, B.; Pomelli, C.; Adamo, C.; Clifford, S.; Ochterski, J.; Petersson, G. A.; Ayala, P. Y.; Cui, Q.; Morokuma, K.; Malick, D. K.; Rabuck, A. D.; Raghavachari, K.; Foresman, J. B.; Cioslowski, J.; Ortiz, J. V.; Stefanov, B. B.; Liu, G; Liashenko, A.; Piskorz, P.; Komaromi, I.; Gomperts, R.; Martin, R. L.; Fox, D. J.; Keith, T.; Al-Laham, M. A.; Peng, C. Y.; Nanayakkara, A.; Gonzalez, C.; Challacombe, M.; Gill, P. M. W.; Johnson, B. G.; Chen, W.; Wong, M. W.; Andres, J. L.; Head-Gordon, M.; Replogle, E. S.; Pople, J. A. Gaussian 98; Gaussian, Inc.: Pittsburgh, PA, 1998.

10. Bader, R. F. W. Atoms in Molecules, A Quantum Theory; Clarendon Press: Oxford, 1994.
11. (a) Margot, J. L.; Nolan, M. C.; Benner, L. A. M.; Ostro, S. J.; Jurgens, R. F.; Giorgini, J. D.; Slade, M. A.; Campbell, D. B. Binary Asteroids in the Near-Earth Object Population. Science 2002, 296, 296-1445. (b) Margot, J. L.; Brown, M. E. A LowDensity M-Type Asteroid in the Main Belt. Science 2003, 300, 1939-1942.

12. Goldreich, P.; Lithwick, Y.; Sari, R. Formation of Kuiper-Belt Binaries by Dynamical Friction and Three-Body Encounters. Nature 2002, 420, 643-646.

13. (a) Morton, T. H. The Reorientation Criterion and Positive Ion-Neutral Complexes. Org. Mass Spectrom. 1992, 27, 353-368. (b) McAdoo, D. J; Morton, T. H. Gas Phase Analogues of Cage Effects. Accts. Chem. Res. 1993, 26, 295-302.

14. (a) Midland, M. M.; Morton, T. H. Is Protonated Ammonium Fluoride an Ion-Neutral Complex in the Gas Phase? J. Am. Chem.. Soc. 1993, 115, 9596-9601. (b) Illies, A. J; Morton, T. H. Strong Hydrogen Bonding in the Gas Phase: Fluoromethane...Hydronium versus Fluoromethane...Ammonium. Int. J. Mass Spectrom. Ion Processes 1997, 167/168, 431-445. (c) Morton, T. H. Decompositions via Ion-Neutral Complexes. The Encyclopedia of Mass Spectrometry. I; Armentrout, P. B., Ed.; Elsevier: London, 2003; 467-479.

15. Solomon, J. J.; Field, F. H. Reversible Reactions of Gaseous Ions. IX. The Stability of $\mathrm{C}_{4}-\mathrm{C}_{7}$ Tertiary Alkyl Carbonium Ions. J. Am. Chem. Soc. 1975, 27, 2625-2628.

16. NIST Chemistry WebBook, NIST Standard Reference Database Number 69; Mallard, W. G.; Linstrom, P. J., Eds.; National Institute of Standards and Technology: Gaithersburg, MD; http://webbook.nist.gov, March 2003.

17. Hammerum, S.; Derrick, P. J. $\alpha$-Cleavage in Amine Molecular Ions. A Not-So-Simple Simple Cleavage. J. Chem. Soc. Chem. Commun. 1985, 996-997.

18. (a) Traeger, J. C.; Djordjevic, M. Heat of Formation for the Vinyl Alcohol Cation by Photoionization Mass Spectrometry. Eur. Mass Spectrom. 1999, 5, 319-324. (b) Traeger, J. C. Heats of Formation for the Propen-1-ol and Propen-2-ol Cations by Photoionization Mass Spectrometry. Int. J. Mass Spectrom. 2001, 210/211, 181-188.

19. Traeger, J. C.; McLoughlin, R. G. Absolute Heats of Formation for Gas-Phase Cations. J. Am. Chem. Soc. 1981, 103, 3647-3652.

20. Chase, M. W.; Davies, C. A.; Downey, J. R.; Frurip, D. J.; McDonald, R. A.; Syverud, A. N. JANAF Thermochemical Tables, 3rd Edition. J. Phys. Chem. Ref. Data 1985, 14, Suppl. 1.

21. Traeger, J. C.; Kompé, B. M. Thermochemical Data for Free Radicals from Studies of Ions. Energetics of Organic Free Radicals; Simões, J. A. M.; Greenberg, A.; Liebman, J. F., Eds.; Chapman and Hall: London, 1996; 59-109.

22. Turecek, F.; Cramer, C. J. Thermochemistry of Simple Enols and Enol Cation Radicals Revisited. A G2(MP2) ab Initio Study. J. Am. Chem. Soc. 1995, 117, 12243-12253.

23. Harvey, Z. A., Traeger, J. C. The Propionyl Cation Heat of Formation Revisited. J. Mass Spectrom., in press.

24. Lias, S. G.; Bartmess, J. E.; Liebman, J. F.; Holmes, J. L.; Levin, R. D.; Mallard, W. G. Gas-Phase Ion and Neutral Thermochemistry. J. Phys. Chem. Ref. Data 1988, 17, Suppl. 1. 